\title{
Correction to: Height, Literacy and Survival: A Composite Index of Wellbeing Based on Data from Military Recruitment $(1880-1980)$
}

\author{
Antonio M. Linares-Luján ${ }^{1}$ (D) · Francisco M. Parejo-Moruno ${ }^{1}$ (D)
}

Published online: 10 April 2019

(c) Springer Nature B.V. 2019

\section{Correction to: Social Indicators Research https://doi.org/10.1007/s11205-019-02077-0}

In the original publication of this article, the acknowledgement section has been published incorrectly. Now the correct text has been provided in this correction.

Acknowledgements The authors want to thank the financial support provided by the Government of Extremadura and by the EU through ERDF funds. Antonio Linares also thanks the financial support provided by the Ministry of Science, Innovation and Universities (HAR2016-76814-C2-2-P) (MINECO/AEI/ FEDER/UE, 2017-2020).

Publisher's Note Springer Nature remains neutral with regard to jurisdictional claims in published maps and institutional affiliations.

The original article can be found online at https://doi.org/10.1007/s11205-019-02077-0.

Antonio M. Linares-Luján

alinares@unex.es

Francisco M. Parejo-Moruno

fmparejo@unex.es

1 Department of Economics, Faculty of Economics and Business, University of Extremadura, Elvas Aveneu s/n, 06071 Badajoz, Spain 